\title{
User-to-Brand Social Media Behavior Directed at Brands and its Impact on Electronic Word-of-Mouth and Purchase Intentions: An Abstract
}

\author{
Youngtae Choi and Michael W. Kroff
}

\begin{abstract}
A group of social media users commonly referenced in the Internet usage literature is made up of passive users. Their activity is generally defined by their following the activities of others. In addition, many users of social media platforms, such as Facebook, interact with brands by making some type of public commentary on their own or the brand's social media page, without offering creative content. This declarative behavior may include offering feedback, suggestions, and opinions or even complaining about specific aspects of the brand. While this group also arguably makes up a considerable number of social media users, little research exists regarding how its behavior might be measured and how it might affect behaviors toward the brands with which this group interacts. This research explores these two specific user-to-brand (u2b) social media behaviors and how they impact user electronic word-of-mouth (eWOM) and purchase intentions (PI). Two constructs are developed, $\mathrm{u} 2 \mathrm{~b}$ content consumption intentions (CConI) and $\mathrm{u} 2 \mathrm{~b}$ content commentary intentions (CComI). Empirical results using structural equation modeling (SEM) provide evidence that CConI impacts CComI and both have a direct and positive impact on eWOM but not on PI, while eWOM has a direct and positive impact on PI. These results suggest that brands can benefit from both the passive behavior of social media users who consistently consume content on brand pages and from more active behavior involving feedback and suggestions directed at brands. A main benefit of these behaviors is increased positive eWOM, which subsequently impacts purchase intentions.
\end{abstract}

\footnotetext{
Y. Choi

University of North Florida, Jacksonville, FL, USA

e-mail: ychoi@unf.edu

M. W. Kroff $(\bowtie)$

Southern Utah University, Cedar City, UT, USA

e-mail: michaelkroff@suu.edu 